\title{
New ways of fluidization in a centrifugal field
}

\author{
J. De Wilde \\ Department of Materials and Process Engineering, \\ Université catholique de Louvain, Belgium
}

\begin{abstract}
Both numerical and experimental observations on two novel technologies for fluidization in a centrifugal field are presented.

In the rotating fluidized bed in a static geometry, the rotating motion of the particle bed is generated by the tangential injection of the fluidization gas in the fluidization chamber via multiple gas inlet slots, so i.e. by the tangential fluidization of the particle bed. The fluidization gas is forced to leave the fluidization chamber via a centrally positioned chimney results in a combined tangential-radial motion of the fluidization gas through the particle bed. In case the radial gas-solid drag force balances the centrifugal force, radial fluidization of the particle bed can be obtained. As a result of the tangential fluidization of the particle bed in rotating fluidized beds in a static geometry, radial fluidization of the particle bed is, however, not necessary to take full advantage of the improved particle bed uniformity and the higher gas-solid slip velocities at which fluidized beds can be operated in a centrifugal field.

The rotating chimney can be combined with any rotating fluidized bed technology and allows increasing locally, i.e. in the vicinity of the chimney, the centrifugal force. The rotating chimney consists of multiple blades and rotates in the same sense than the rotating particle bed, but at higher rotational speeds. The fluidization gas is forced through the chimney blades to the chimney outlet. As a result of the centrifugal force generated by the rotating chimney, particles are not entrained by the fluidization gas, but remain rotating around the chimney in a fluidized state.
\end{abstract}

Keywords: fluidization, rotating fluidized bed, rotating chimney, process intensification, centrifugal force. 


\section{Introduction}

Fluidization in the earth gravitational field faces limitations in the gas-solid slip velocities and in the particle size that can be used. The limitation in the gas-solid slip velocity may induce external mass and heat transfer limitations, that is, in the gas-solid mass and heat transfer rates [1]. The limitation in the particle size may induce internal mass transfer limitations. Internal heat transfer limitations can usually be neglected by the large heat capacity of the particles.

Fluidization in a centrifugal field may allow to overcome the above mentioned limitations [2]. In the currently existing so-called rotating fluidized beds, the fluidization chamber is rotated fast around its axis of symmetry by means of a motor in order to generate a centrifugal field [2-6]. The particles form a cylindrically shaped particle bed against the outer cylindrical wall of the fluidization chamber. Radial fluidization of the particle bed is introduced by injecting the fluidization gas radially through perforations in the outer cylindrical wall of the fluidization chamber and by evacuating the fluidization gas via a centrally positioned chimney. It should be emphasized that in the current type of rotating fluidized beds, the particle bed is only radially fluidized by balancing the centrifugal force and the radial gas-solid drag force.

The current type of rotating fluidized beds has never been used on a large scale in the (petro)chemical industries. Major challenges encountered were related to the moving geometry, i.e. the rotating fluidization chamber, and include sealing, vibrations, particle feeding and removal, etc.

In the present work, two novel technologies for fluidization in a centrifugal field are presented and discussed: the rotating fluidized bed in a static geometry and the rotating chimney [7-9]. The present paper does not aim to give a detailed overview of experimental or simulation results, but rather summarizes the concept, the recent findings, and the potential of the novel technologies.

\section{Rotating fluidized beds in a static geometry}

\subsection{The concept}

In a rotating fluidized bed in a static geometry [7,9], the rotating motion of the particle bed is generated by the tangential injection of the fluidization gas in the fluidization chamber via multiple gas inlet slots in its outer cylindrical wall (Figure 1). The fluidization gas is forced to leave the fluidization chamber via a centrally positioned chimney. Whereas in the current rotating fluidized beds, the motion of the fluidization gas through the particle bed is mainly radial, in rotating fluidized beds in a static geometry, the fluidization gas is forced to move in a combined tangential-radial way through the particle bed. This is at the origin of the unique characteristics of rotating fluidized beds in a static geometry with respect to flexibility in the fluidization gas flow rate. Indeed, as can be theoretically shown [9] and as will be demonstrated in what follows, in rotating fluidized beds in a static geometry, the fluidization gas flow rate affects the centrifugal force and the counteracting radial gas-solid drag force in a similar 
way. This allows to vary the fluidization gas flow rate while hardly affecting the radial bed expansion or the particle losses via the chimney.

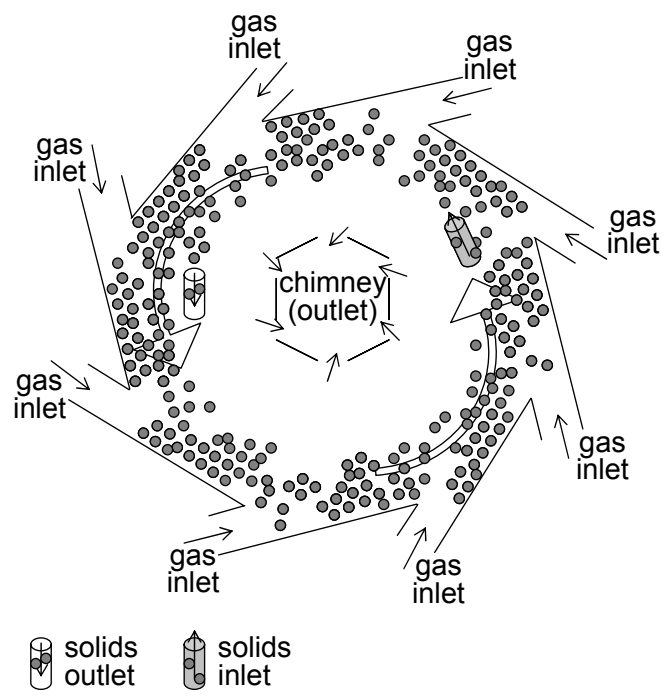

Figure 1: The concept of the rotating fluidized bed in a static geometry.

\subsection{Basic experimental observations}

Experiments were carried out using two different fluidization chamber designs and two different types of particles. The major fluidization chamber design parameters and particle characteristics are listed in Table 1. The first fluidization chamber has a cylindrical design and is $24 \mathrm{~cm}$ in diameter. The second fluidization chamber has a polygonal design and is $36 \mathrm{~cm}$ in diameter. The particles of the 1G-Geldart D-type are polymer pellets with an average size of $3.5 \mathrm{~mm}$ and a density of $950 \mathrm{~kg} \mathrm{~m}^{-3}$. The particles of the $1 \mathrm{G}-\mathrm{Geldart} \mathrm{B}$-type are alumina or salt particles with an average size of $350 \mu \mathrm{m}$ and a density of about $2160 \mathrm{~kg} \mathrm{~m}^{-3}$.

Independent of the fluidization chamber design, the particles fluidized, or the fluidization gas flow rate, the solids loading in the fluidization chamber was found to be crucial in obtaining a stable rotating fluidized bed in a static geometry (e.g. Figure 2 for the 24-cm diameter fluidization chamber and the polymer particles). At very low solids loadings, channelling is observed. In the case of channelling, a strongly non-uniform distribution of the particles and the fluidization gas in the axial direction of the fluidization chamber is observed. At somewhat higher solids loadings, slugging occurs (Figure 2). In the case of slugging, a strongly non-uniform distribution of the particles and the fluidization gas in the tangential direction occurs. A particle slug forms that rotates in the fluidization chamber and most of the fluidization gas enters the fluidization chamber via the gas inlet slots not facing the resistance of a particle bed [9]. At 
sufficiently high solids loadings, a stable rotating fluidized bed is formed, rendering the gas-solid contact optimal (Figure 2). It should be emphasized that the fluidization gas flow rate has only a minor impact on the flow regime that is obtained in rotating fluidized beds in a static geometry (Figure 2).

This can be explained by the similar effect of the fluidization gas flow rate on the centrifugal force and the counteracting radial gas-solid drag force, a major feature of rotating fluidized beds in a static geometry.

Table 1: Fluidization chamber and particle characteristics.

\begin{tabular}{|l|l|l|}
\hline & Unit & Value \\
\hline $\begin{array}{l}\text { Fluidization } \\
\text { chamber } \\
\text { diameter }\end{array}$ & {$[\mathrm{m}]$} & $\begin{array}{l}\text { (i) } 24 \cdot 10^{-2} \text {, cylindrical } \\
\text { (ii) } 36 \cdot 10^{-2}, \text { polygonal }\end{array}$ \\
\hline $\begin{array}{l}\text { Fluidization } \\
\text { chamber } \\
\text { length }\end{array}$ & {$[\mathrm{m}]$} & $\begin{array}{l}13.5 \cdot 10^{-2} \\
11.5 \cdot 10^{-2} \text { (rotating chimney) }\end{array}$ \\
\hline $\begin{array}{l}\text { Chimney } \\
\text { diameter }\end{array}$ & {$[\mathrm{m}]$} & $\begin{array}{l}\text { (i) } 15 \cdot 10^{-2} / 16 \cdot 10^{-2} \text { (rotating chimney) } \\
\text { (ii) } 12 \cdot 10^{-2}\end{array}$ \\
\hline $\begin{array}{l}\text { Number of } \\
\text { tangential } \\
\text { gas inlet slots }\end{array}$ & {$[/]$} & $\begin{array}{l}\text { (i) } 12 \text { or } 24 \\
\text { (ii) } 12\end{array}$ \\
\hline $\begin{array}{l}\text { Gas inlet } \\
\text { slot width }\end{array}$ & {$[\mathrm{m}]$} & $\begin{array}{l}\text { (i) } 2.3 \cdot 10^{-3} \\
\text { (ii) } 4 \cdot 10^{-3}\end{array}$ \\
\hline $\begin{array}{l}\text { Number of } \\
\text { chimney } \\
\text { outlet slots }\end{array}$ & {$[/]$} & $\begin{array}{l}1 \\
32(\text { rotating chimney) }\end{array}$ \\
\hline $\begin{array}{l}\text { Chimney } \\
\text { outlet slot } \\
\text { width }\end{array}$ & {$[\mathrm{m}]$} & $\begin{array}{l}\text { (i) } 8 \cdot 10^{-2} \\
\text { (ii) } 9 \cdot 10^{-2}\end{array}$ \\
\hline $\begin{array}{l}\text { Number of } \\
\text { solids inlets } \\
\text { and outlets }\end{array}$ & {$[/]$} & $\begin{array}{l}1 / 1, \\
\text { via opposite end plates }\end{array}$ \\
\hline $\begin{array}{l}\text { Total gas } \\
\text { flow rate }\end{array}$ & {$\left[\mathrm{Nm}{ }^{3} \mathrm{~h}^{-1}\right]$} & $650-850$ \\
\hline $\begin{array}{l}\text { Outlet } \\
\text { pressure }\end{array}$ & {$[\mathrm{Pa}]$} & 101300 \\
\hline Temperature & {$[\mathrm{K}]$} & 333 \\
\hline $\begin{array}{l}\text { Particle } \\
\text { material }\end{array}$ & {$[/]$} & $\begin{array}{l}\text { a) polymer } \\
\text { b) salt } / \text { alumina }\end{array}$ \\
\hline $\begin{array}{l}\text { Average } \\
\text { particle size }\end{array}$ & {$[\mathrm{m}]$} & $\begin{array}{l}\text { a) } 2 \cdot 10^{-3}\left(\text { length)-5·1 } 10^{-3} \text { (diameter) }\right. \\
\text { (cylinder pellets) }\end{array}$ \\
\hline $\begin{array}{l}\text { Particle } \\
\text { density }\end{array}$ & {$\left[\mathrm{kg} \mathrm{m}^{-3}\right]$} & $\begin{array}{l}\text { a) } 950 \cdot 10^{-6} \\
\text { b) } 2160\end{array}$ \\
\hline
\end{tabular}




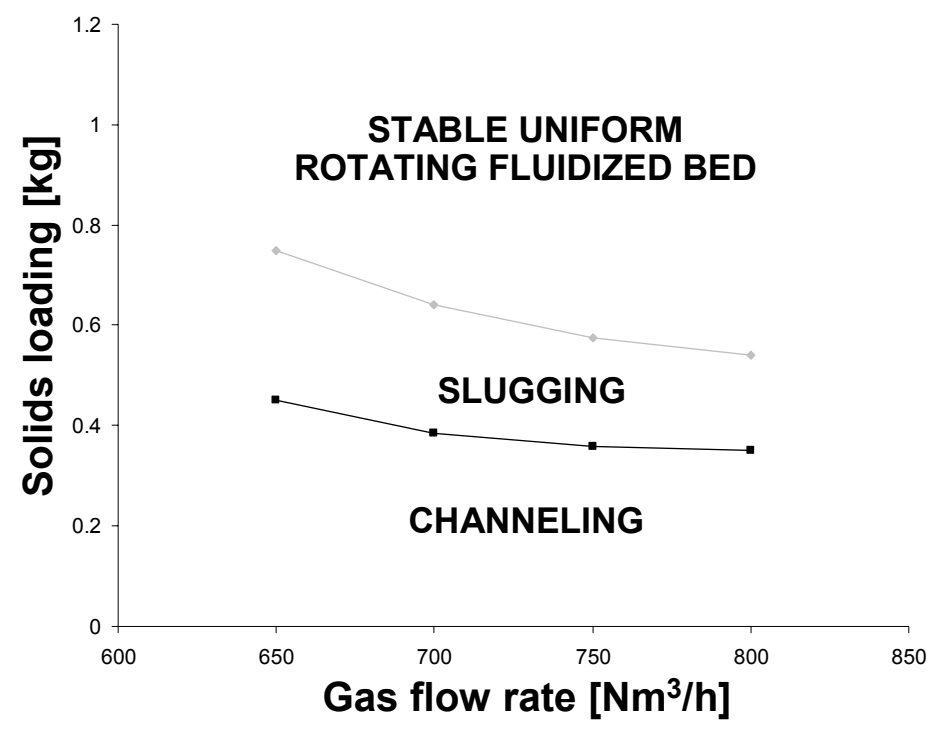

Figure 2: Different flow regimes as a function of the fluidization gas flow rate and the solids loading in the fluidization chamber. Fluidization chamber and particle characteristics: see Table 1, (i) and (a).

Figure 3 shows the typical experimentally observed behaviour at sufficiently high solids loadings with the two different types of particles using the same nonoptimized 24-cm diameter fluidization chamber design. Similar observations were found with the 36-cm diameter fluidization chamber design [9]. The main difference in the behaviour of the two types of particles is found in the radial bed expansion, that is, the radial fluidization of the rotating particle bed. With the polymer particles, radial fluidization is nearly absent. As a result, an excellent separation of the particles and the fluidization gas leaving the fluidization chamber is obtained with minimal particle losses via the chimney. Despite the absence of radial fluidization of the particle bed, particle mixing is pronounced by the tangential fluidization that is introduced. The absence of radial fluidization indicates an unbalance between the centrifugal force and the radial gas-solid drag force. This implies that part of the centrifugal pressure generated by the rotating motion of the particle bed is supported by the outer cylindrical wall of the fluidization chamber, i.e. the rotating particle bed is pushed against the outer cylindrical wall of the fluidization chamber. The unbalance of the centrifugal force and the radial gas-solid drag force when using the polymer particles with the current fluidization chamber designs can be theoretically proven [9] and is confirmed by a comparison of the measured centrifugal pressure drop, derived from the measured particle bed rotational speed and solids loading in the fluidization chamber, and the measured radial pressure drop over the particle bed. With the alumina or salt particles, radial fluidization of the rotating particle bed is pronounced and bubble formation is observed (Figure 3). 
Bubbles are transported in a combined tangential-radial motion through the particle bed [9]. Furthermore, most of the fluidization gas injected via one gas inlet slot is seen to leave the particle bed when approaching the next downstream gas inlet slot. This was confirmed by simulations ( $\$ 2.3)$. As a result of the radial bed expansion, the separation between the particles and the fluidization gas leaving the fluidization chamber is somewhat less good than with the polymer particles and the particle losses via the chimney are pronounced. The balance between the centrifugal force and the radial gas-solid drag force can be theoretically calculated, confirming radial fluidization using the alumina or salt particles with the current fluidization chamber designs.

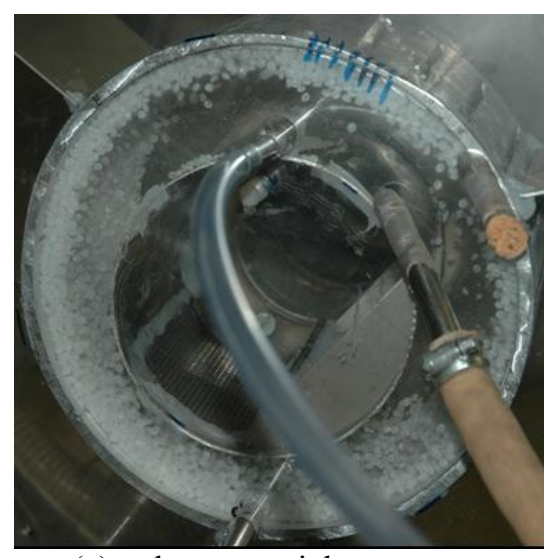

(a) polymer particles

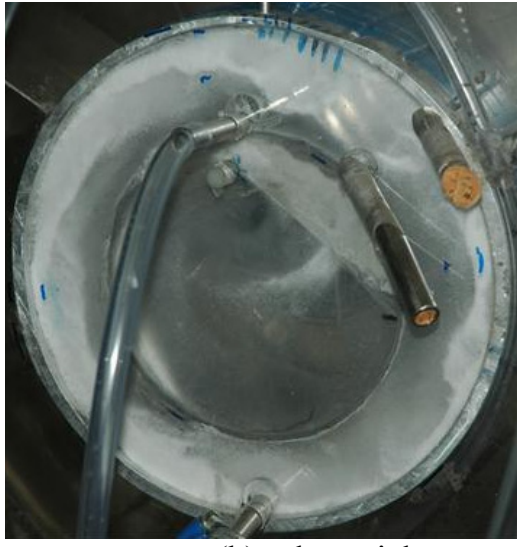

(b) salt particles

Figure 3: $\quad$ Rotating fluidized bed in a static geometry.(a): polymer particles (Table 1: (i), (a)); (b): salt particles (Table 1: (i), (b)).

\subsection{Numerical investigation}

Computational Fluid Dynamics (CFD) simulations were carried out to improve comprehension of the gas-solid flow behaviour in rotating fluidized beds in a static geometry. The Eulerian-Eulerian approach [10] was taken and the solid phase physico-chemical properties were calculated using the Kinetic Theory of Granular Flow (KTGF) [11]. Calculations were carried out using the Fluent code. Figure 4 shows some typical simulation results for a $36-\mathrm{cm}$ diameter fluidization chamber and the salt particles. Whereas the simulation model or code fails to predict certain experimental observations, as for example bubble formation [9], other experimental observations are clearly confirmed. Upstream of each gas inlet slot, solids accumulation occurs (Figure 4(a)). The fluidization gas injected via a given gas inlet slot is seen to move radially inwards when approaching the next downstream gas inlet slot (Figure 4(b)). This results in a local tangential deceleration of the particle bed. The inertia of the solids prevents them from following the fluidization gas radially inwards (Figure 4(c)) and is at the origin of the solids accumulation upstream of the gas inlet slots. 

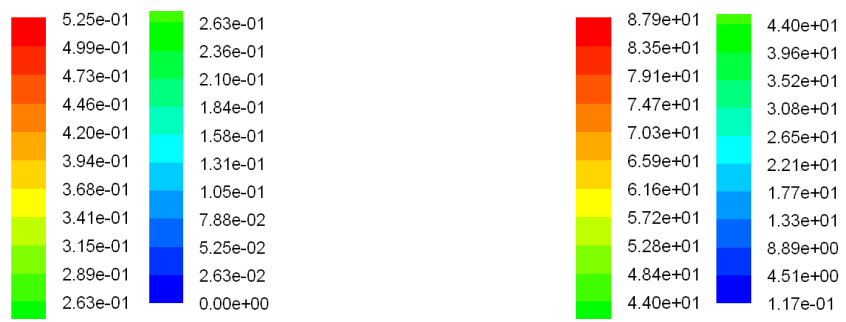

(a)

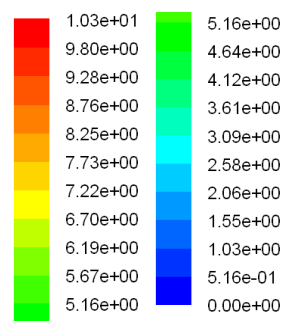

(c)

Figure 4: CFD simulation of a rotating fluidized bed in a static geometry.(a) solids volume fraction; (b) gas phase velocity vectors, coloured by the gas phase velocity magnitude; (c) solids velocity vectors coloured by the solids velocity magnitude. Focus on a region in the vicinity of a gas inlet slot.

\subsection{Potential applications}

Both the experimental observations (e.g. Figure 2) and the numerical simulations confirm the extreme flexibility in the fluidization gas flow rate when using rotating fluidized beds in a static geometry. In particular, this allows operating rotating fluidized beds in a static geometry at much higher, that is, one to several orders of magnitude higher gas-solid slip velocities than conventional fluidized beds. On the one hand, this implies that the residence time of the fluidization gas in the particle bed, i.e. the gas-solid contact time can be made very short. On the other hand, a higher gas-solid slip velocity implies a proportionally higher gassolid mass and heat transfer coefficient. The possible combination of extremely short gas-solid contact times and extremely high gas-solid mass and heat transfer coefficients renders rotating fluidized beds in a static geometry potentially advantageous for use with extremely fast and highly endo- or exothermic reactions. For certain catalytic reactions, the removal of external mass or heat transfer limitations when using rotating fluidized beds in a static geometry will allow using a more active catalyst and the increase of the overall reaction rate. Internal mass transfer limitations could be removed by using smaller particles [1]. Indeed, even micro- and nano-scale particles were shown to fluidize uniformly in a sufficiently high centrifugal field [12,13]. Summarizing, by allowing operation at significantly higher gas-solid slip velocities and by a 
similar impact of the fluidization gas flow rate on the centrifugal force and the counteracting radial gas-solid drag force, rotating fluidized beds in a static geometry pave the way for fluidized bed process intensification, i.e. the use of more compact reactors, and for an improved flexibility in fluidized bed operation.

\section{Rotating chimney}

\subsection{The concept}

When fluidizing small particles, in particular micro- and nano-size particles, in any type of rotating fluidized bed, particle entrainment by the fluidization gas to the chimney may be pronounced. To avoid excessive particle losses via the chimney, the chimney design can be modified or a rotating chimney [8] can be used.

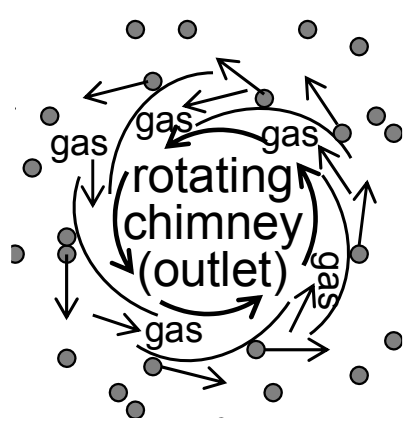

Figure 5: The concept of the rotating chimney.

The rotating chimney consists of multiple blades with inlets to the chimney in between them (previously called 'fluidization chamber outlets') and rotates fast around its axis of symmetry by means of a motor (Figure 5). The fluidization gas is forced to move from the region outside the chimney into the chimney by means of a compressor. Particles in the region outside the chimney cannot follow the fluidization gas into the chimney by the action of the centrifugal force generated by the chimney rotational motion. In case the centrifugal force by the chimney and the radial gas-solid drag force in the vicinity of the chimney are balanced, a rotating fluidized bed around a rotating chimney can be obtained, as will be confirmed by the simulations presented further in this work. In case the centrifugal force by the chimney is much stronger than the radial gas-solid drag force in the vicinity of the chimney, particles will, at contact with the chimney, be ejected more strongly. In such case and if the rotating chimney is used in combination with another rotating fluidized bed technology $[2,5,7,9]$, the rotating chimney allows to build up more easily a high solids loading in the rotating fluidized bed against the outer cylindrical wall of the fluidization chamber. This has been experimentally demonstrated, as will be shown in the next paragraph. 


\subsection{Basic experimental observations}

The action of the rotating chimney was experimentally investigated in combination with a rotating fluidized bed in a $24-\mathrm{cm}$ diameter static fluidization chamber [7,9] and using polymer or salt particles. The fluidization chamber, chimney and particle characteristics are summarized in Table 1.

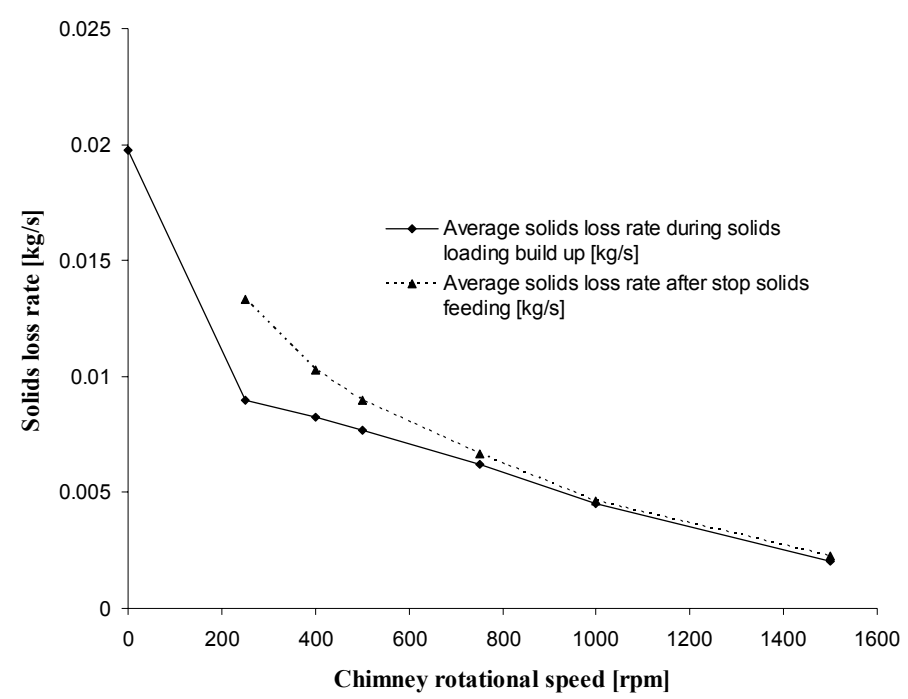

(a)

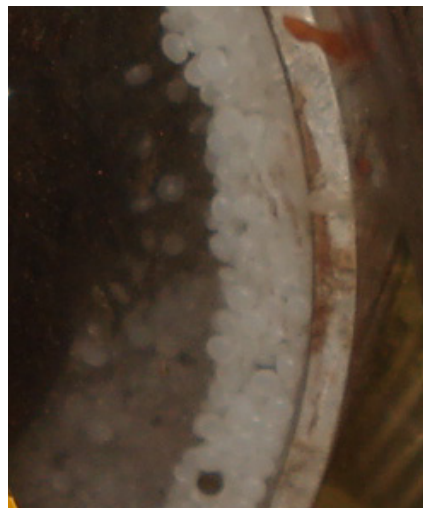

chimney: $250 \mathrm{rpm}$

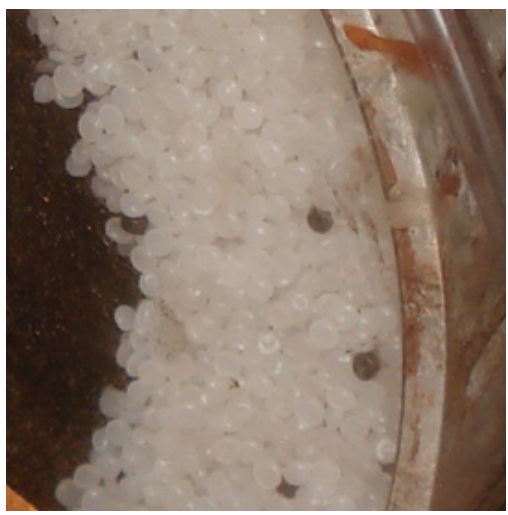

chimney: $1000 \mathrm{rpm}$

(b)

Figure 6: (a) Solids loss rate via the chimney as a function of the chimney rotational speed; (b) maximum solids loading in the fluidization chamber for a chimney rotational speed of respectively $250 \mathrm{rpm}$ and $1000 \mathrm{rpm}$. Fluidization chamber and particle characteristics: see Table 1 (i) and (a). Fluidization gas flow rate $=850 \mathrm{Nm}^{3} / \mathrm{h}$; solids feeding rate $=0.0356 \mathrm{~kg} / \mathrm{s}$. 
The typical experimentally observed behaviour is illustrated in Figure 6 using the polymer particles. For a given solids loading in the fluidization chamber and fluidization gas flow rate, the particle losses via the chimney decrease significantly with increasing chimney rotational speed (Figure 6(a)). For a given solids feeding rate and fluidization gas flow rate, on the other hand, a significantly higher solids loading in the fluidization chamber can be obtained with increasing chimney rotational speed (Figure 6(b)). These findings hold for the salt particles.

\subsection{Numerical investigation}

Numerical simulations were carried out to demonstrate the formation of a rotating fluidized bed of small size particles around a rotating chimney. The simulation model and method used are described in $\S 2.3$. The rotating chimney in combination with the static outer cylindrical wall of the fluidization chamber requires the use of a rotating geometry. The mesh used for the simulations is split into two zones, one static and the other rotating together with the chimney. At the interface between the two mesh zones, an interpolation scheme is used for the exchange of information between the two mesh zones.

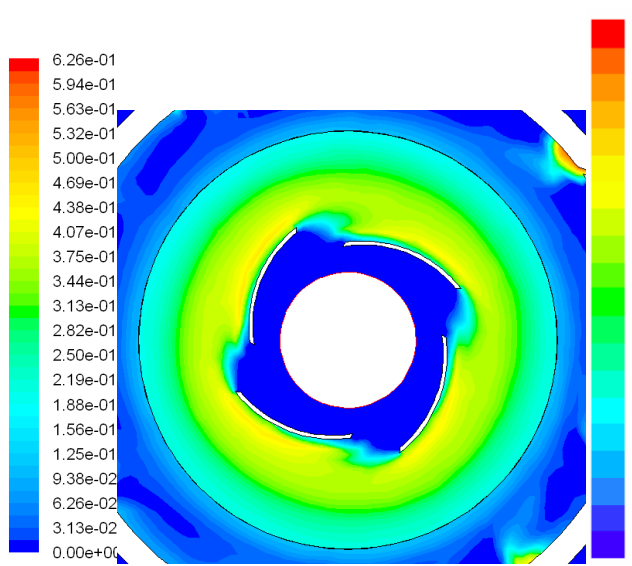

(a)

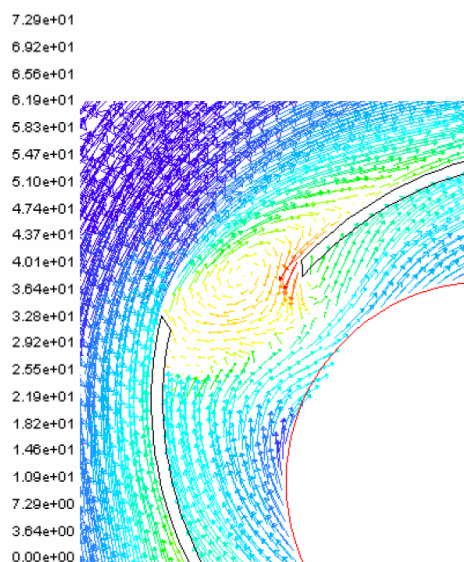

(b)

Figure 7: $\quad$ Simulation of a rotating fluidized bed of $60 \mu \mathrm{m}$ alumina particles around a rotating chimney. (a) Solids volume fraction; (b) Solids velocity vectors relative to the chimney rotational motion, coloured by the absolute solids velocity magnitude. Focus on a zone between two blades.

Figure 7(a) shows the simulated solids volume fraction profile in a $36-\mathrm{cm}$ diameter fluidization chamber with a 4-blade, $12-\mathrm{cm}$ diameter rotating chimney when fluidizing $60 \mu \mathrm{m}$ alumina particles. The chimney rotational speed is 4000 rpm (rotations per minute). Figure 7(a) clearly demonstrates that, whereas the fluidization gas is forced to leave the fluidization chamber via the openings 
between the chimney blades, the particles cannot follow the fluidization gas into the chimney and form a rotating fluidized bed around the rotating chimney.

Figure 7(b) shows the vectors of the solids velocity relative to the chimney rotational motion coloured by the absolute solids velocity magnitude, focusing on a region between two chimney blades. As seen from Figure 7(b), particles eventually entrained into the chimney by the fluidization gas can be returned to the rotating particle bed around the chimney by the rotating motion of the chimney. This is an important feature of rotating chimneys.

\subsection{Potential applications}

When used with other rotating fluidized bed technologies, rotating chimneys allow to increase locally, that is, in the vicinity of the chimney, the centrifugal force. As such, rotating chimneys can significantly reduce or even eliminate particle losses via the chimney. This may be of particular importance when fluidizing small, i.e. micro- or nano-scale, particles [12,13]. Furthermore, in certain applications, the particle size changes significantly during the residence time of the particles in the fluidization chamber. In such cases, the rotating chimney opens perspectives for multi-zone or multi-layer fluidized bed technology, with, for example, a rotating fluidized bed of the largest particles near the outer cylindrical wall of the fluidization chamber and a rotating fluidized bed of smaller particles near the chimney.

\section{Conclusions}

Two novel technologies for fluidization in a centrifugal field are presented and experimentally and numerically investigated. In rotating fluidized beds in a static geometry, the rotating motion of the particle bed and the centrifugal force are generated by the tangential injection of the fluidization gas via multiple gas inlet slots in the outer cylindrical wall of the fluidization chamber. The combined tangential-radial motion of the fluidization gas through the particle bed results in extreme flexibility with respect to the fluidization gas flow rate and, as such, with respect to the gas-solid mass and heat transfer coefficients. With rotating chimneys, the centrifugal force is generated by the rotational motion of the chimney. The radial gas-solid drag force resulting from the fluidization gas being forced into the chimney counteracts the centrifugal force generated by the chimney. In combination with conventional rotating fluidized beds or rotating fluidized beds in a static fluidization chamber, rotating chimneys allow to significantly reduce the particle losses via the chimney and to operate at higher solids loadings in the fluidization chamber. As such, rotating chimneys significantly increase the flexibility in operation of rotating fluidized beds. Rotating chimneys may be particularly advantageous when fluidizing small particles or mixtures of particles with different fluidization properties.

\section{Acknowledgements}

Axel de Broqueville is greatly acknowledged for the scientific collaboration and for the financial support of the research. Luc Wautier is greatly acknowledged 
for the technical realization of the project and for the help with the experiments. I would like to thank CISM of the Université catholique de Louvain for the use of their computational facilities.

\section{References}

[1] Froment, G.F., Bischoff, K.B., Chemical Reactor Analysis and Design, Wiley Series in Chemical Engineering, Second Edition, 1990.

[2] Chen, Y.-M., Fundamentals of a centrifugal fluidized bed, AIChE J., 33(5), pp. 722-728, 1987.

[3] Kroger, D.G., Levy, E.K., Chen, J.C., Flow characteristics in packed and fluidized rotating beds, Powder Technol., 24(1), pp. 9-18, 1979.

[4] Fan, L.T., Chang, C.C., Yu, Y.S., Takahashi, T., Tanaka, Z., Incipient fluidization condition for a centrifugal fluidized bed, AIChE J., 31(6), pp. 999-1009, 1985.

[5] Qian, G.-H., Bagyi, I., Burdick, I.W., Pfeffer, R., Shaw, H., Stevens, J.G., Gas-solid fluidization in a centrifugal field, AIChE J., 47(5), pp. 10221034, 2001.

[6] Watano, S., Nakamura, H., Hamada, K., Wakamatsu, Y., Tanabe, Y., Dave, R.N., Pfeffer, R., Fine particle coating by a novel rotating fluidized bed coater, Powder Technol., 141, pp. 172-176, 2004.

[7] de Broqueville, Axel : Catalytic polymerization process in a vertical rotating fluidized bed : Belgian Patent 2004/0186, Internat. Classif. : B01J C08F B01F; publication number : 1015976A3.

[8] de Broqueville, A., De Wilde, J., Central rotating chimney apparatus for obtaining a rotating fluidized bed in a cylindrical fixed or rotating fluidization chamber and processes using this apparatus, April 23, 2007: PCT/EP2007/053941 (F-995-WO), European and United States of America patent application.

[9] De Wilde, J., de Broqueville, A., Rotating Fluidized Beds in a Static Geometry: Experimental Proof of Concept, AIChE J., 53(4), pp. 793-810, 2007.

[10] Anderson, T., Jackson, R., A Fluid Mechanical Description of Fluidized Beds, Industrial \& Engineering Chemistry Fundamentals, 6, pp. 527-539, 1967.

[11] Gidaspow, D., Multiphase Flow and Fluidization: Continuum and Kinetic Theory Descriptions, Academic Press, 1994.

[12] Watano, S., Imada, Y., Hamada, K., Wakamatsu, Y., Tanabe, Y., Dave, R.N., Pfeffer, R., Microgranulation of fine powders by a novel rotating fluidized bed granulator, Powder Technol., 131, pp. 250-255, 2003.

[13] Quevedo, J., Pfeffer, R., Shen, Y., Dave, R., Nakamura, H., Watano, S., Fluidization of nanoagglomerates in a rotating fluidized bed, AIChE J., 52(7), pp. 2401-2412, 2006. 